\title{
Conservation of defence heritage structures using corrosion protection techniques
}

\author{
R. Brueckner \& P. Lambert \\ Mott MacDonald, Materials and Corrosion Engineering, UK
}

\begin{abstract}
Defence structures have been built in various forms since mankind started to settle. The type of structures and materials used have become more sophisticated over time and in particular more resistant but no structure or material to date may be considered to be indestructible. Recent building materials and construction methods can be highly resistant to weathering and damage but under certain exposure conditions may still show signs of weakness and deterioration.

The main cause of materials deterioration in late $19^{\text {th }}$ century structures or modifications onwards is often a result of corrosion of ferrous materials such as steel reinforcement in concrete structures, the structural steel frame in buildings plus other embedded metallic items. Corrosion of embedded metals causes tensile stresses as a result of the more voluminous corrosion products, leading to cracking or delamination of the exterior.

Modern technologies based on electrochemistry, such as cathodic protection, re-alkalisation, electro-chemical chloride extraction and corrosion inhibitors, have been developed and applied to address the risk of corrosion in marine and civil infrastructure. However, the same technologies can also discreetly be applied to conserve heritage structures without unduly affecting the appearance.

Where aggressive species such as chlorides are not present in sufficient quantities to dominate the degradation mechanisms, it is still possible to achieve durable repairs using what are essentially traditional repair technologies. Keywords: corrosion, cathodic protection, concrete, steel frame, heritage,
\end{abstract}

\section{Introduction}

Historic and modern construction materials can have significantly different properties. While they all are capable of providing a certain resistance against the 
environmental conditions, they share one common property in that their service life is not indefinite. Natural materials are commonly more long lasting than man-made materials, but even natural stone suddenly exposed to the atmosphere can be affected by erosion, abrasion and freeze-thaw action. Manmade materials have the tendency to go back to their original physical condition, which is usually a low energy and stable form.

Metallic items undergo energy intensive processes to get into the shapes we require for fabrication and construction. Iron and steel are particularly prone to decomposition or corrosion as they want to go back into their stable low energy condition [1].

Ferrous materials have been around since the Iron Age but were only used as principal construction materials in significant volumes from the $19^{\text {th }}$ century onwards when reinforced concrete was developed. The use of steel frames in the construction of buildings became popular at the beginning of the $20^{\text {th }}$ century when the then common materials brick, stone masonry and concrete could not satisfy the requirements to build higher and more efficiently. This form of construction using a steel frame was initially employed in Chicago and subsequently used in most major cities in the USA and Europe. Ferrous materials as secondary, nonstructural materials, can however be found in almost all historic structures, often as later modifications to stabilise or strengthen the more traditional materials.

Their desire to return to the stable low energy state - to corrode or rust - can cause significant problems to the structural integrity and appearance of buildings. Conservation and restoration of heritage structures typically needs to avoid a significant alteration in appearance and therefore relatively new, less intrusive technologies may be considered advantageous in preventing deterioration as a result of corrosion. Such techniques include:

- Cathodic protection;

- Electrochemical chloride extraction and re-alkalisation;

- Electro-osmosis;

- Corrosion inhibitors.

\section{Corrosion of steel}

In the presence of moisture and oxygen, steel and other simple ferrous alloys undergo corrosion resulting in a loss of metal and the formation of expansive corrosion products commonly referred to as rust. The rate and nature of the process depends on alloy composition, environmental factors, design and the presence of additional protection. In its simplest form the corrosion process can be represented by two dissimilar metals in an aqueous electrolyte, joined to allow electrons to pass from anode to cathode with an associated loss of metal from the anodic areas. In reality, when a metal corrodes, anodic and cathodic areas can be formed on a single surface in contact with the aggressive aqueous environment. This is shown in Figure 1. As a result, corrosion can occur at a large number of sites over the surface of the metal. Dissolved metal ions react with hydroxyl ions to form the corrosion products [2]. 
The relative humidity of an environment has a profound effect on the rate of corrosion of steel. There is a critical level of relative humidity below which corrosion does not occur and often secondary and tertiary levels above that when the corrosion rate increases significantly. In the case of steel, corrosion commences at a slow rate at approximately $60 \% \mathrm{RH}$, the rate increases at $75-80 \%$ $\mathrm{RH}$ and again at $90 \%$. Contamination of the environment, such as the presence of salts, has a tendency to reduce the relative humidity at which corrosion initiates [3].

Controlling the relative humidity of encased steel can provide an effective means of controlling corrosion. The removal or exclusion of excess moisture also removes or prevents the ingress of potentially aggressive species. As most of the moisture and other mobile species that influence durability must cross the boundary between substrate and atmosphere, the application of coatings and surface treatments can be highly effective at limiting or preventing degradation, subject to aesthetic and heritage considerations [4].

\section{ELECTROLYTE}

(Water in mortar,

soil, or concrete)

Current carried by

ions

\section{IN THE ELECTROLYTE}

Anions move to the anode

(hydroxide, chloride, sulphate)

Cations move to the cathode

(hydrogen, sodium, calcium)

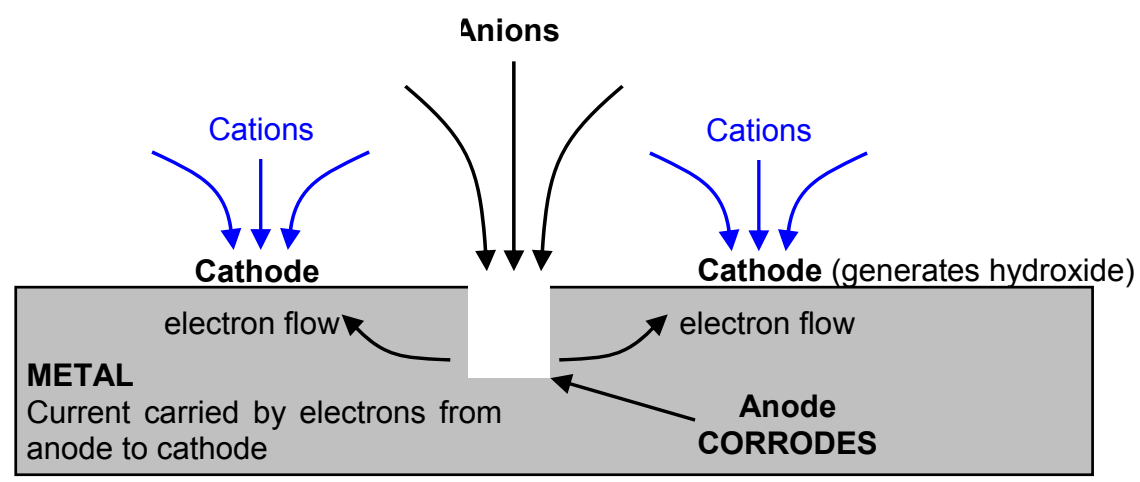

Figure 1: The corrosion process.

\section{Cathodic protection}

Cathodic protection (CP), originally developed by Humphry Davy [5] and later employed widely on buried and submerged structures, was first considered for reinforced concrete in the late 1950s. It was not until the development of improved anode systems based on catalysed titanium and titanium oxide in the early 1980s and the considerable advances in digital operating systems that it became a serious commercial solution. The transfer to steel framed buildings was somewhat slower 
and it was not until 1997 that the first full structure, Gloucester Road Underground Station [6] was protected by such a system.

\subsection{Reinforced concrete structures}

Steel in concrete is usually protected against corrosion by a passivation layer on the surface of the steel as a result of the high alkalinity in the cement paste. This passivation layer can however be destroyed as a result of carbonation of the surrounding concrete, which reduces the $\mathrm{pH}$ in the cement paste, or the presence of chloride which may derive from internal or external sources. This has been discussed in more detail in [7].

Reinforced concrete can be cathodically protected using various methods by means of an impressed current cathodic protection (ICCP) or galvanic (sacrificial) system. Both systems work by polarising the reinforcement in an electrical circuit so the anodic, metal-dissolving mechanism is forced to take place at an installed anode. ICCP systems generally use inert long-life electrode such as mixed metal oxide coated titanium. The reinforcement is polarised using an external DC power source. Galvanic systems use less noble metal electrodes, commonly zinc, aluminium or magnesium, which corrode preferentially to the steel and thereby provide the required protection.

For heritage structures it is important that the original appearance is maintained which can be achieved by installing a cathodic protection system comprising of discrete anodes which, as in the case of Gloucester Road Underground Station can be installed from the inside of the building and lost behind wall finishes.

Thorverton Bridge is a good example of the approach required to apply CP to an historic reinforced concrete structure, Figure 2. This bridge is the man access to a small village in Devon in the south west of England. It dates from 1908 and is the oldest reinforced concrete bridge in Devon. In this case there were two requirements for the structure. Significant corrosion was identified due to carbonation of the concrete. Little chloride contamination was found in spite of the fact the structure had been regularly treated with chloride based de-icing salts. In addition to this the structure had been identified as understrength under the 40 tonne assessment programme and required bringing up to strength.

The solution developed was based on casting additional concrete arches between the existing arches. A cathodic protection system was installed to ensure durability. The cathodic protection was based on discrete anodes comprising a coated titanium rod inserted into a carbonaceous gel. The anodes were up to $0.5 \mathrm{~m}$ long and were interlinked using titanium wire back to a central power and control unit. The monitoring system was routed back to a remote system that could be monitored and adjusted via modem.

\subsection{Steel framed buildings}

Over the last 75 to 100 years since construction of steel framed masonry clad buildings, the protection offered by the surrounding masonry has broken down and the steel has corroded resulting in cracking and displacement of cladding as higher volume corrosion has filled up the gaps, as shown in Figure 3. In extreme cases, 
Defence Sites II 275

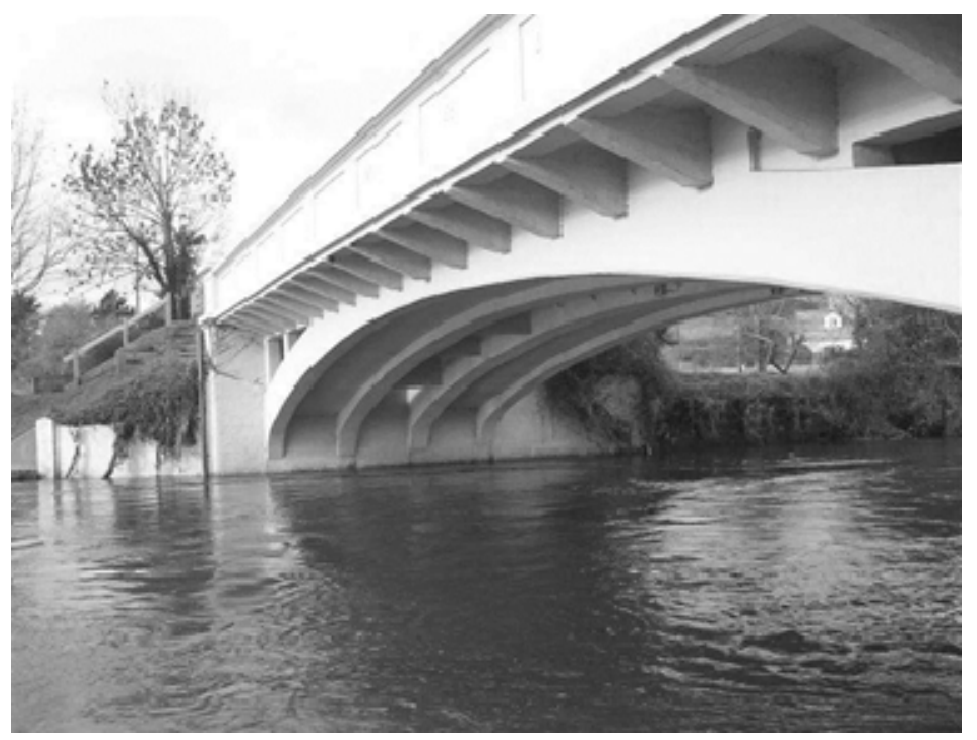

Figure 2: $\quad$ Thorveton Bridge.

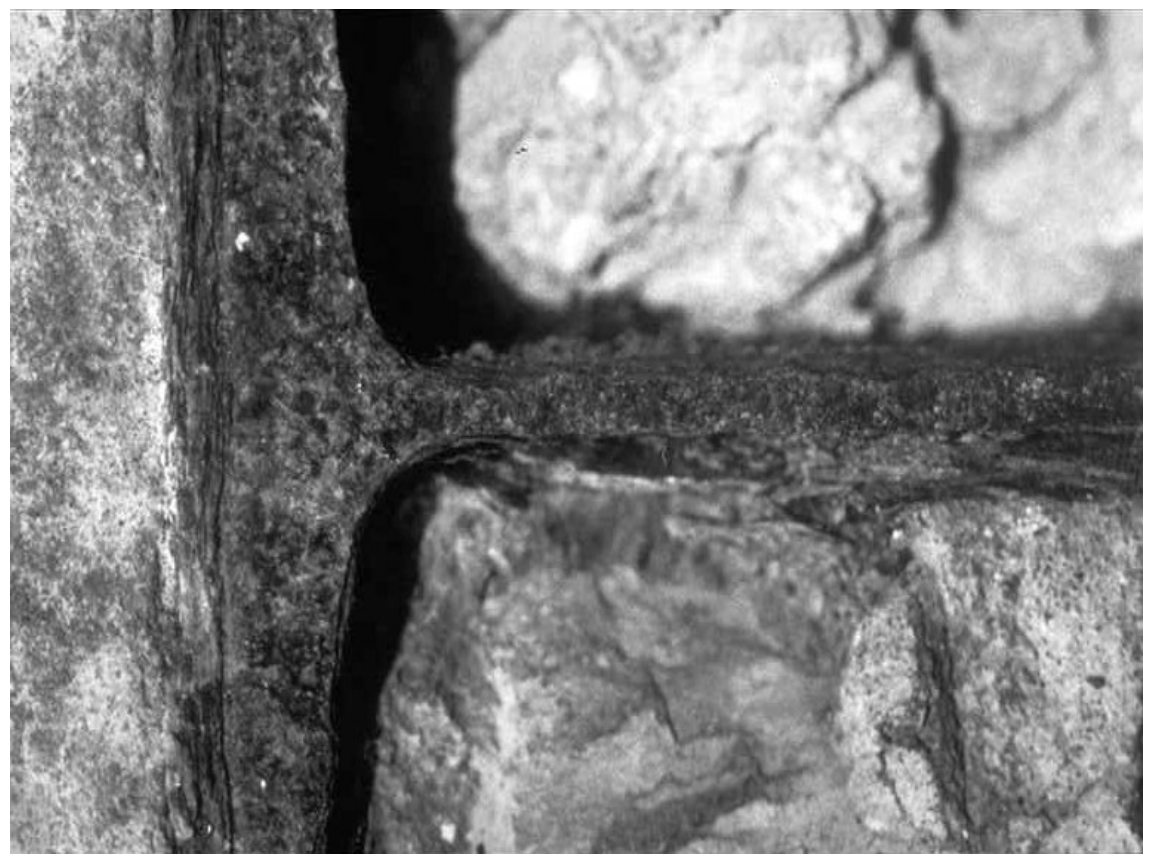

Figure 3: Corrosion of a masonry encased wrought iron beam. 
the steel members have lost sufficient section to impair their structural capacity, requiring the inclusion of new or additional steel.

Traditional methods of repair require the displaced masonry to be removed and the corroded frame to be cleaned and recoated prior to reinstating the cladding. This is not only disruptive and expensive, but generally leaves large areas of corrosion where no displacement of the masonry has occurred untreated and the level of damage to the masonry will commonly require new material to be employed in the reconstruction, thereby undermining the authenticity of the structure.

CP of such structures, introduced toward the end of the last century, has provided a technically feasible and commercially viable alternative to the repair and maintenance of such structures and continues to gain favour in such applications. Details of such systems have been described in detail elsewhere [8].

\section{Electrochemical chloride extraction and re-alkalisation}

The application of CP can result in a number of potentially beneficial side effects. The ferrous component, being the cathode in a corrosion cell, generates hydroxyl ions which help maintain a passive oxide film on the surface of the steel and helps protect it from further corrosion. In addition, because the cathode is negatively charged, ions such as chloride are repelled from the steel and attracted to the inert anodes.

While these processes occur naturally as a consequence of $\mathrm{CP}$, they can also be optimised as remediation treatments in their own right. The claimed benefit of such techniques is that they can be applied temporarily in order to increase the alkalinity or reduce chloride levels and then be removed. This means that the affected material can be treated in situ and potentially returned to its original condition and appearance. Commercially these techniques are referred to as electrochemical chloride extraction (ECE) and re-alkalisation, although the former has in the past sometimes been confusingly referred to as 'desalination' [9].

Both techniques employ a temporary anode system held on the surface of the concrete within an electrolyte, either by means of tanks or in the form of a papier mâché poultice. For chloride extraction the electrolyte is commonly calcium hydroxide solution as this prevents the generation of chlorine at the anode surface. For realkalisation, the electrolyte is usually a solution of sodium or potassium carbonate which permeates into the concrete through a mixture of diffusion and electro-osmosis and helps reinstate the alkalinity of the cover concrete.

\section{Electro-osmosis}

The application of a DC current across a porous solid can generate movement of moisture due to electro-osmosis. While techniques such as CP, ECE and realkalisation result in a small effect, electro-osmosis as a technique in its own right has been applied to the movement of moisture through porous materials such as masonry for a considerable time and with varying results. Most recent systems 
employ low voltage DC pulses designed to operate at maximum efficiency while avoiding problems of stray-current corrosion to adjacent metallic items.

Where reinforcement or other metallic items are present, the design, installation and monitoring of the system should prove simpler than for existing electrochemical remediation techniques. Such systems are capable of reducing moisture levels to between $60 \%$ and $70 \% \mathrm{RH}$, and maintaining this level irrespective of external weather conditions. An additional benefit to the removal of excess free moisture is the associated reduction in dissolved salts such as chlorides and sulphates.

The combination of reduced chloride ion concentration and controlled relative humidity can result in a significant reduction in corrosion rate for reinforcement or other embedded metallic items to low or negligible values. The continuing operation of an appropriately designed and installed system can prevent or control further ingress of moisture and associated dissolved salts. Additionally, if the system is designed to negatively polarise reinforcement this results in a degree of cathodic protection, helping to reduce the corrosion risk of embedded steel during the transition period from high to low relative humidity and providing additional protection throughout the life of the installation [4].

\section{Corrosion inhibitors}

Corrosion inhibitors are widely used in the protection of metals in domestic, commercial and industrial applications. A corrosion inhibitor is essentially any material that when present in a relative small quantity results in a significant reduction in the corrosion rate of metals, predominantly the ferrous based materials such as iron and steel. There has long been interest in their potential use for the protection of metallic reinforcement in concrete and other structural materials.

Inorganic inhibitors such as nitrites and benzoates have been used as anticorrosive admixtures in concrete since the 1950s, principally as admixtures introduced at the time of manufacture. A more recent development has been the development of organic inhibitor systems that can be applied to the surface which then migrate to and protect buried metallic components. These materials are commonly based on amino-alcohols and are capable of migrating through masonry and concrete to form a highly adherent microscopic film covering the surface of the metal and thereby protect it.

Because the surface of the porous material to which they are applied is unaltered, they allow the protection of embedded metals without altering the appearance of the structure. The service life of the inhibitor, typically several years, is dependent upon the porosity of the material and severity of the environment but can be easily reapplied. Figure 4 shows a Grade 1 listed structure at the former Royal Aircraft Establishment in Farnborough, UK where corrosion inhibitors were employed to protect the reinforcement while retaining the original weathered appearance of the concrete [10]. Other recent applications for corrosion inhibitors have included cramps and wall ties and the protection of historically important industrial sites with wax-based corrosion inhibiting coatings. 


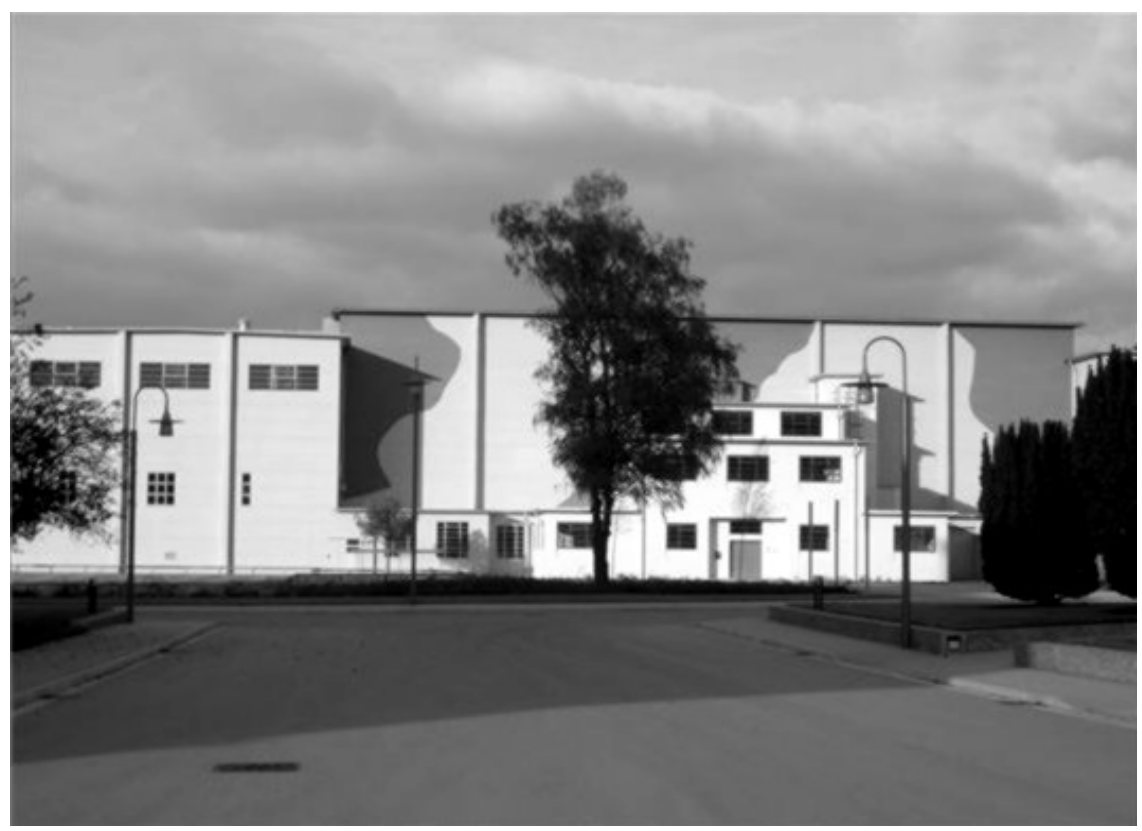

Figure 4: Wind tunnel buildings at RAE Farnborough, partly protected by inhibitors [10].

\section{Conventional repair}

While in many cases, the presence of chloride ions makes conventional repair unattractive as a durable option due to the risks of incipient anode behaviour, this is not always the case and in their absence it is still possible to carry out durable repair by relatively conventional means. Two examples where this approach has been possible and successfully carried out are outlined below.

\subsection{Queensway Tunnel, Merseyside}

The Queensway Tunnel joins Liverpool to Birkenhead in the North West of England. It was designed by Sir Basil Mott and construction started in 1925. The design of the deck is a Hennebique based system. In this system the reinforcement starts in the top of the deck by the supports then cracks into the soffit of the deck across the mid span. At the time of construction cover to the reinforcement was considered a fire protection issue only with no regard to durability and so the steel is relatively close to the surface of the concrete.

After a routine inspection significant corrosion of the deck soffit was identified. This was due to carbonation, accelerated by the dry air being constantly blown over the surface of the concrete. Chloride testing was undertaken on the top of the deck and significant chloride was identified throughout the tunnel, despite the fact 
that the tunnel had never been de-iced. This was attributed to vehicular traffic tracking chlorides in from the surrounding area.

The repair procedure was complicated by the access. Whilst there was plenty of room under the main bore, in order to get to this area access was via limited access passages, Figure 5. Based on the difficulties in accessing the job the repair
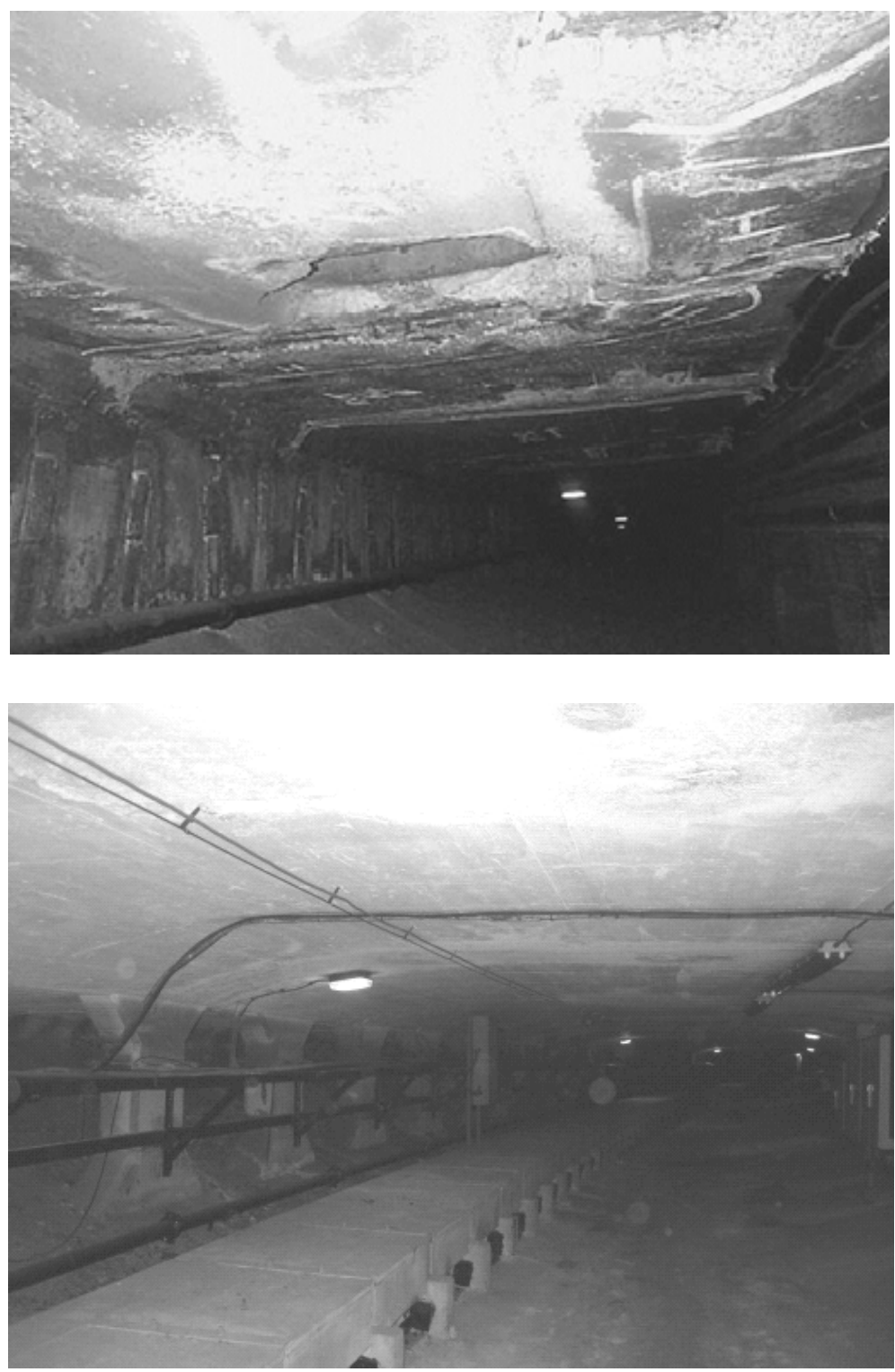

Figure 5: Queensway Tunnel Deck Soffit - prior to repair, approximately 60 years old (top) and 20 years after repairs were completed (bottom). 
process was developed using ultra high water pressure jetting to remove all loose and delaminated concrete, and dry sprayed concrete to reinstate the removed concrete. All spoil had to be removed and all materials had to be brought to the area of work via the same limited access points.

\subsection{The White Tower, Blackpool}

The White Tower building in Blackpool is a fine example of Art Deco style, Figure 6. The building was constructed in 1939. The external envelope was original made up of white Portland cement with a quartz aggregate. Over the years it had succumbed to extensive chloride contamination. In addition it had been coated and patch repaired many times. In 2005 a $£ 500,000$ repair project was undertaken. Due to the extent of degradation and previous repairs it was not possible to restore the original finish to the structure as little of it remained.

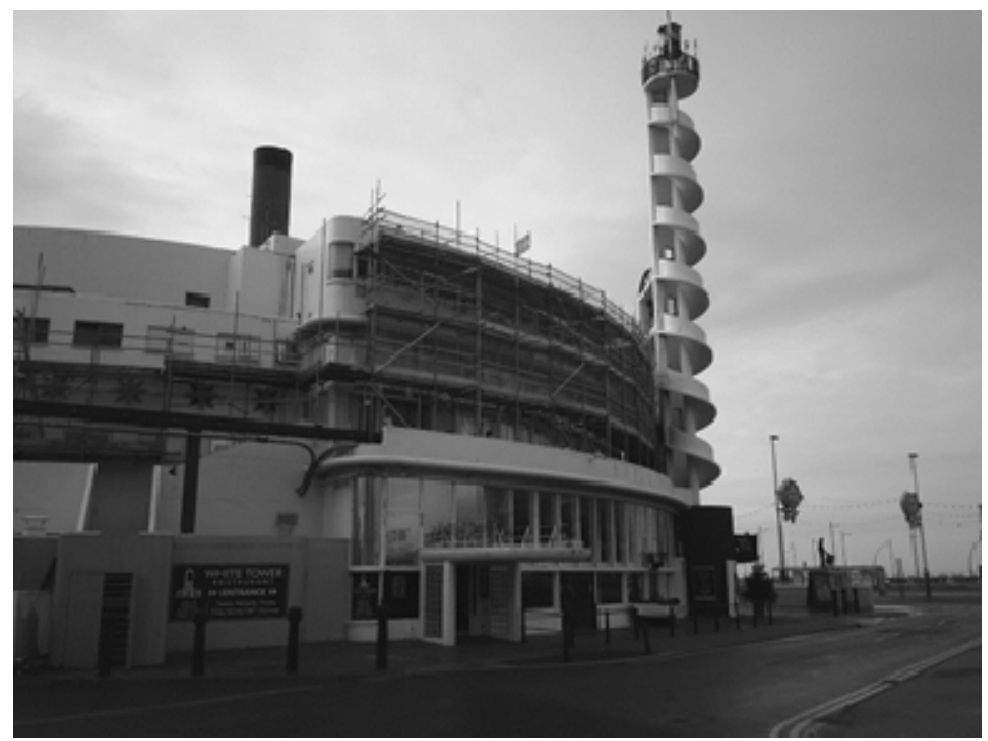

Figure 6: The White Building, Blackpool, during refurbishment.

One further problem was that in some of the larger elements areas the exterior façade was made up using permanent formwork to achieve the high quality finish. The reinforcement was placed in the formwork and backfilled with conventional concrete, in a procedure similar to that used by Frank Lloyd Wright. This gives the initial impression of a high quality finish, however the concrete behind the façade is of poor quality, heavily voided and rapidly degrades.

The repair procedure involved the removal of all loose and delaminated concrete and reinstatement with appropriate repair materials. In spite of the benefits that cathodic protection normally provides in minimising the extent of breakout, it was not appropriate for this structure as the façade was made up of many individual precast elements. This would have required a very complex $\mathrm{CP}$ 
system which would have precluded the repair contract. Once the repairs were completed the whole structure was recoated. The structure owner has introduced a rolling programme of inspections to enable the maintenance of the building to be better planned and more closely controlled.

\section{Conclusions}

By combining the best practices of traditional methods with more recently developed repair techniques it is possible to develop remediation strategies for a wide range of historic structures that are cable of providing very long extensions in service life with minimal levels of intrusion and disruption to the original structural fabric.

Electrochemical techniques such as cathodic protection can be particularly valuable when preserving metallic items vulnerable to corrosion. The technique itself is nearly 200 years old and therefore predates the majority of the structures it is employed to protect.

Where corrosion is not subject to the influence of aggressive species, most notably chlorides, it remains possible to carry out durable repairs without the need for additional corrosion above that provided by sound materials and well planned and timely maintenance.

\section{References}

[1] Lambert P, 'Sustainability of metals and alloys in construction', Sustainability of Construction Materials, Woodhead Publishing, pp. 148170, 2009.

[2] Lambert, P., 'Corrosion mechanisms - An introduction to aqueous corrosion', Technical Note No. 5, Corrosion Prevention Association, UK, 4pp., 2002.

[3] Vernon, W.H.J., 'A laboratory study of the atmospheric corrosion of metals' Trans. Faraday Society, 31, 1935.

[4] Lambert, P., 'Controlling moisture', Construction Repair, 6, pp. 29-32, March/April 1997.

[5] Davy H, 'On the corrosion of copper sheeting by seawater, and on methods of preventing this effect, and on their application to ships of war and other ships'. Proceedings of the Royal Society, 114, pp. 151-246, 1824 and 115 , pp. 328-346, 1825.

[6] Evans B, 'Electric refurbishment', The Architects' Journal, pp. 59-61, November 1997.

[7] Brueckner R. \& Lambert P., 'Present day problems with historic innovations'. In: Proceedings of $1^{\text {st }}$ International Conference on Defence Sites: Heritage and Future 2012, Portsmouth, UK, Wessex Institute of Technology, 6-8 June 2012, pp. 81-92.

[8] Lambert P \& Atkins C P, 'Cathodic protection of historic steel framed buildings', Structural Studies, Repairs and Maintenance of Heritage Architecture XI, Malta, pp. 491-500, 2005. 
[9] McFarland B, 'Electrochemical repair using realkalisation and chloride extraction techniques', Concrete Repair Association Guidance Note, 1999.

[10] Williams N, 'Tunnel vision - historic concrete conservation', Concrete, pp. 30-31, February 2008. 